\title{
An Experimental Study of the Use of Coconut Oil-based PCM to Reduce the Thermal Load of Air Conditioners as an Effort to Save Energy
}

\section{Kajian Eksperimental Penggunaan PCM Berbasis Minyak Kelapa untuk Mengurangi Beban Termal AC Sebagai Upaya Penghematan Energi}

Agung Ariwibowo ${ }^{1 *}$, Muhammad Irsyad ${ }^{1}$, Amrul $^{1}$

\begin{abstract}
The use of air conditioning affects energy consumption. Thermal load is a big factor that affects energy consumption by air conditioners. For this reason, the thermal load of a room needs to be reduced. One strategy to reduce the room's thermal load is the use of phase change materials (PCM). Coconut oil is a PCM that has a freezing temperature in the range of $21.30-21.73$ oC which will be investigated in this study. The test was carried out with three room models; without PCM, with PCM partition, and PCM partitioned with night air. Each room model carried out 3 variations of air temperature, as well as 4 variations of the heater. The results showed that the use of coconut oil PCM as a room partition can help reduce the room temperature to $2^{\circ} \mathrm{C}$ below the AC temperature with a decrease in the use of electrical energy reaching 400 Watts.
\end{abstract}

\section{Keywords}

PCM, PCM partition wall, coconut oil-based PCM

\begin{abstract}
Abstrak
Air conditioner (AC) merupakan alat untuk mengondisikan udara pada sebuah ruangan. Penggunaannya berdampak pada konsumsi energi listrik. Beban termal menjadi faktor besar yang mempengaruhi konsumsi energi oleh AC. Untuk itu beban termal dari sebuah ruangan perlu dikurangi. Salah satu strategi untuk mengurangi beban termal ruangan yaitu penggunaan phase change material (PCM). Minyak kelapa merupakan PCM yang memiliki suhu beku dengan rentang 21,30 - 21,73 ${ }^{\circ} \mathrm{C}$ yang akan diteliti kali ini. Pengujian dilakukan dengan tiga model ruangan yaitu non $P C M$, berpartisi PCM, dan berpartisi PCM dengan udara malam. Masing-masing model ruangan dilakukan 3 variasi temperatur udara, serta 4 variasi heater. Hasil penelitian menunjukkan bahwa penggunaan PCM minyak kelapa sebagai partisi ruangan dapat membantu menurunkan temperatur ruangan sampai $2^{\circ} \mathrm{C}$ dibawah temperatur $A C$ dengan penurunan penggunaan energi listrik mencapai $400 \mathrm{Watt}$.
\end{abstract}

\section{Kata kunci}

$P C M$, dinding berpartisi $P C M$, dan $P C M$ minyak kelapa

${ }^{1}$ Teknik Mesin, Universitas Lampung

Jl. Prof. Dr. Ir. Sumantri Brojonegoro No.1, Gedong Meneng,

Kec. Rajabasa, Kota Bandar Lampung, Lampung 35141

*email: agunghs91@gmail.com

Submitted : January 24, 2022. Accepted :February 23, 2022. Published : February 25, 2022. 


\section{PENDAHULUAN}

Air Conditioning (AC) merupakan alat yang saat ini banyak digunakan untuk mengondisikan udara di dalam ruangan sehingga memperoleh kenyamanan termal ruangan. Kenyamanan termal adalah kondisi manusia merasa nyaman ketika berada di dalam ruangan. Tentang Konservasi Energi Sistem Tata Udara Bangunan Gedung, pemenuhan kenyamanan termal suatu ruang kerja berkisar antara $24{ }^{\circ} \mathrm{C}$ sampai $27^{\circ} \mathrm{C}$ atau $25,5{ }^{\circ} \mathrm{C}+/-1,5{ }^{\circ} \mathrm{C}$ [1] . Penggunaan $A C$ pada bangunan memberikan dampak terhadap konsumsi energi listrik bangunan. Sekitar $60 \%$ konsumsi listrik hotel di Jakarta digunakan untuk memasok energi untuk $A C$ [2]. Oleh karena itu, mengurangi beban termal dari sebuah ruangan menjadi strategi untuk menghemat energi.

Beban termal disebuah ruangan menjadi penyebab beban pendinginan $A C$ meningkat. Tentang Konservasi Energi Sistem Tata Udara Bangunan Gedung, beban pendinginan sebuah ruangan meliputi: Beban selubung bangunan, beban listrik pencahayaan, beban penghuni (manusia), beban udara/cahaya luar, dan beban sistem [3]. Beban pendinginan tersebut yang menyebabkan $A C$ memiliki beban yang besar. Besarnya beban pendinginan akan mempengaruhi konsumsi listrik yang dibutuhkan $A C$ ketika bekerja. Phase Change Material (PCM) dapat digunakan untuk pemanasan dan pendinginan ruang aktif dan pasif [4]. Secara umum $P C M$ dapat diterapkan dalam bahan bangunan seperti beton, papan dinding, gipsum di langit-langit, atau lantai untuk meningkatkan kapasitas penyimpanan termal bangunan. Mereka dapat menangkap energi panas secara langsung melalui konveksi alami. Dengan adanya $P C M$ beban termal ruangan dapat dikurangi sehingga konsumsi energi listrik dari pengunaan $A C$ dapat dikurangi. Bahan perubahan fasa (PCM) sebagai teknologi penyimpan energi yang dikenal memiliki potensi yang tinggi untuk meningkatkan efisiensi yang tinggi pada bangunan. Pemanfaatan PCM pada sektor bangunan juga dapat digunakan sebagai sumber efesiensi sebuah energi yang mana saat ini penggunaannya harus dihemat [5].

Pada penelitian lain dikemukakan bahwa Penggunaan enkapsulasi PCM pada batako berongga dapat menurunkan kondiktivitas termal hingga 19,5\%, dan untuk penggunaan PCM dalam box pada dinding bagian dalam dapat menurunkan temperatur permukaan dinding bagian dalam hingga $30{ }^{\circ} \mathrm{C}$ [6]. Sedangkan penyimpanan energi dingin mengunakan perubahan fasa material $(P C M)$ sangat baik diaplikasikan pada bangunan karena memiliki suhu lebur yang baik. Berdasarkan studi numerik dan eksperimen yang dilakukan, penggunaan PCM pada bangunan dapat mengurangi beban puncak $A C$. [7]. Pemilihan sebuah material perubah fasa yang akan digunakan untuk mengurangi termal ruangan, tentunya harus memiliki titik beku dan titik leleh yang sesuai dengan kenyamanan termal suatu ruangan. Pengujian terhadap material minyak kelapa didapat suhu beku dengan rentang $21,30-21,73^{\circ} \mathrm{C}$ [8]. Dengan suhu tersebut minyak kelapa sangat cocok digunakan sebagai material perubah fasa dengan memanfaatkan potensi suhu dingin di Indonesia ketika malam hari. Berdasarkan uraian tersebut maka perlu adanya penelitian penggunaan $P C M$ minyak kelapa pada dinding bangunan yang dilihat berdasarkan variasi pengaturan $A C$ dan Heater yang digunakan sebagai penganti beban termal ruangan. Penelitian ini dilakukan dengan melihat perpindahan panas yang terjadi pada $P C M$ terhadap temperatur ruangan dan energi yang digunakan alat pengkondisi udara atau $A C$ pada setiap perlakukan variasi pengaturan $A C$ dan Heater.

\section{METODE PENELITIAN}

Penelitian dan pengambilan data dilaksanakan di Laboratrium Teknik Mesin Fakultas Teknik Universitas Negeri Lampung. Waktu penelitian dilakukan bulan September 2020 sampai dengan Desember 2020. Alat yang digunakan dalam pelaksanaan peneltian ini meliputi: Air conditioning (AC), thermokopel, wattmeter, jam, meteran, heater, kipas angin, 
blower, paralon, dan anemometer. Sedangkan bahan yang digunakan adalah Phase Change Material (PCM) jenis minyak kelapa (coconut oil), alumunium hollow, sterofoam, dan resin. Gambar 1 menunjukkan skema pemasangan alat dan bahan.

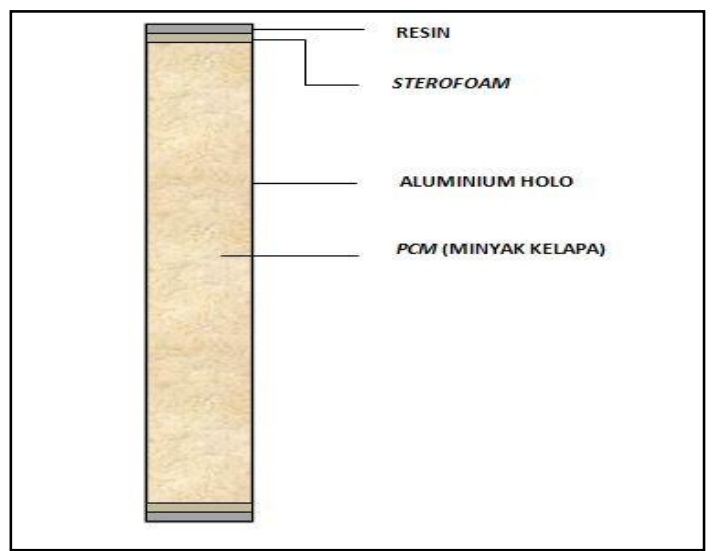

Gambar 1. Pengepakan PCM pada Alumunium hollow

Eksperimen dilakukan pada suhu $A C 18^{\circ} \mathrm{C}, A C 20^{\circ} \mathrm{C}$, dan $A C 22^{\circ} \mathrm{C}$ dan dilakukan variasi heater sebagai pengganti beban termal sebesar 200 watt, 400 watt, 600 watt dan 800 watt dengan waktu kerja 8 jam pada tiap perlakuan. Pengambilan data temperatur dilakukan menggunakan termokopel untuk pendeteksi suhu dan wattmeter untuk pengukur daya listik. Terdapat 7 area yang dipasang termokoplel. Adapun ketujuh area tersebut adalah pertama terletak di depan blower $A C$, kedua di atas $A C$, ketiga pada dinding luar bangunan, keempat pada dinding dalam bangunan, kelima terletak di depan hembusan udara heater, keenam pada input udara heater, ketujuh terletak pada lingkungan ruangan. Pengambilan data dengan model partisi PCM, ditambah 2 termokopel yang diletakan di dalam PCM dan di luar partisi PCM.

\section{HASIL DAN PEMBAHASAN}

\section{Laju perpindahan panas $P C M$}

$P C M$ merupakan material perubah fasa yang digunakan sebagai alat bantu pendinginan pasif pada ruangan. PCM yang digunakan pada pengambilan data ini adalah minyak kelapa yang dimasukkan pada alumunium hollow dan ditempatkan pada dinding-dinding dengan posisi vertikal seperti pada Gambar 2. PCM melepaskan kalor pada saat ruangan didinginkan mengunakan $A C$. Laju perpindahan panas $P C M$ dilihat pada variasi pengaturan $A C 18^{\circ} \mathrm{C}, A C$ $20^{\circ} \mathrm{C}$, dan $A C 22^{\circ} \mathrm{C}$. Pada setiap variasi pengaturan AC dilakukan penggantian heater sebagai beban termal yaitu 200 watt, 400 watt, 600 watt dan 800 watt dengan waktu kerja 8 jam pada tiap perlakuan. Berdasarkan perlakuaan tersebut maka didapatkan hasil temperatur PCM yang dapat dilihat pada Gambar 2 .

Gambar 3 menunjukan temperatur $P C M$ untuk masing-masing variasi. Temperatur terendah PCM yang di tunjukan yaitu pada pengaturan $\mathrm{AC} 18{ }^{\circ} \mathrm{C}$, dimana temperatur PCM terendah diperoleh $22^{\circ} \mathrm{C}$. Dari temperatur terendah yang ditunjukkan PCM disimpulkan bahwah PCM belum mengalami perubahan fasa dengan sempurna. Perubahan fasa menjadi beku minyak kelapa akan mengalami supercooling sampai temperatur $20^{\circ} \mathrm{C}$ hingga $19^{\circ} \mathrm{C}$ [8].

Tingginya temperatur PCM yang ditampilkan pada gambar 3 dapat disebabkan karena besarnya beban termal pada ruangan. Beban termal yang ditimbulkan heater pada ruangan berpengaruh pada laju perpindahan panas pada PCM. Laju perpindahan panas rata-rata pada PCM dapat dihitung menggunakan persamaan:

$$
\dot{Q}_{p c m}=\frac{m \cdot C p \cdot \Delta T}{\Delta t}
$$


Keterangan:

$\dot{Q}_{P C M} \quad$ : Laju perpindahan panas PCM (Watt)

$m \quad$ : Massa $P C M$

$C_{p} \quad:$ Panas jenis (J/kg.K)

$\Delta T \quad$ : Beda temperatur $\left({ }^{\circ} \mathrm{K}\right)$

$\Delta t \quad$ : Waktu (s)

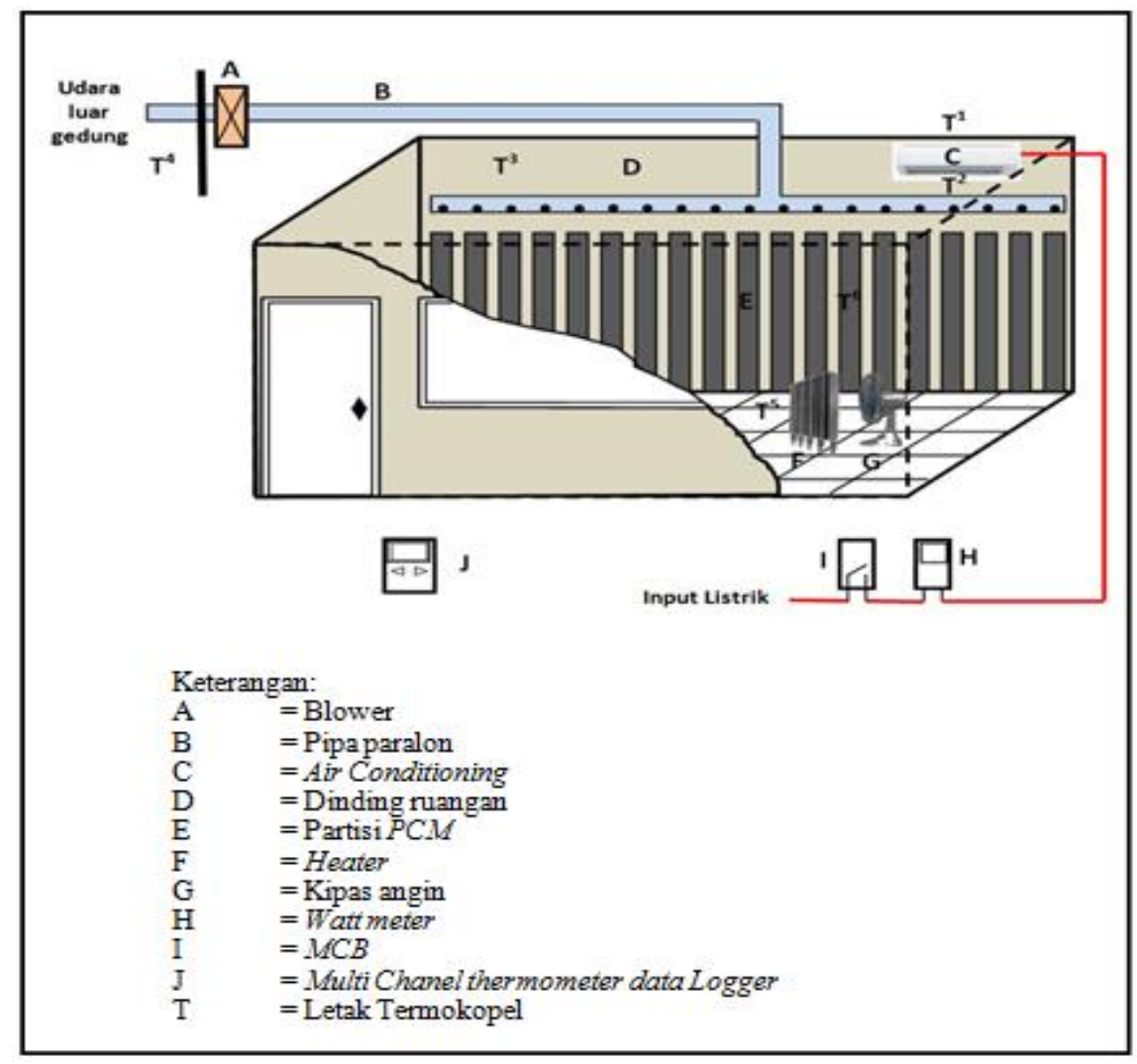

Gambar 2. Skema pemasangan alat dan bahan

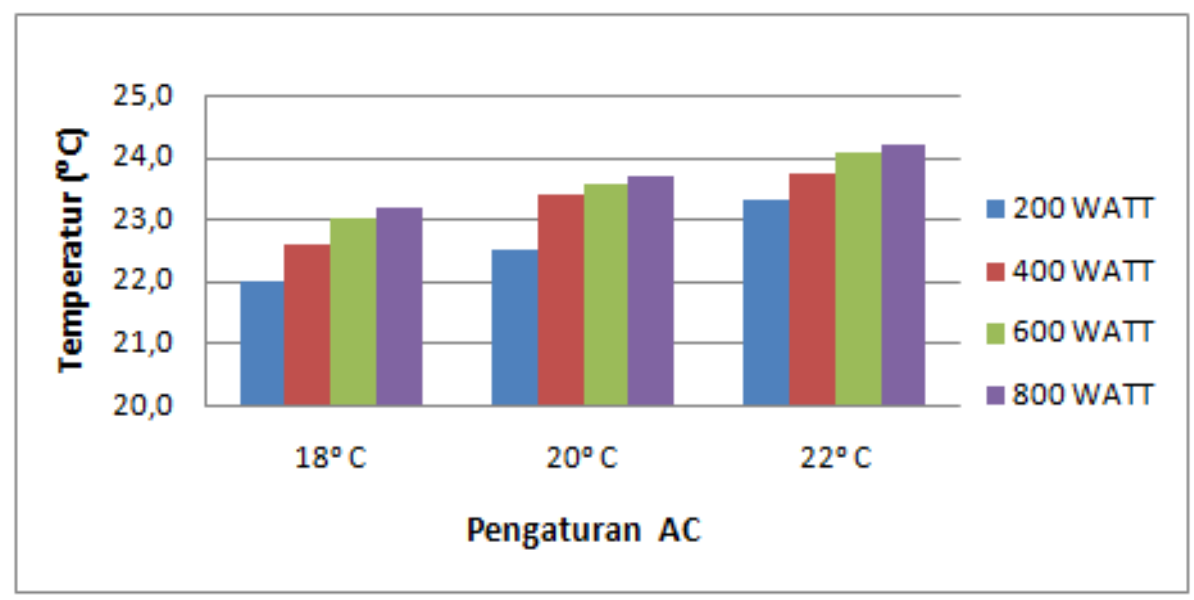

Gambar 3. Temperatur PCM pada setiap variasi Heater dan $A C$

Berdasarkan perhitungan, melihat laju perpindahan panas yang ditinjau tiap 30 menit pada PCM dapat dilihat pada Gambar 4. 


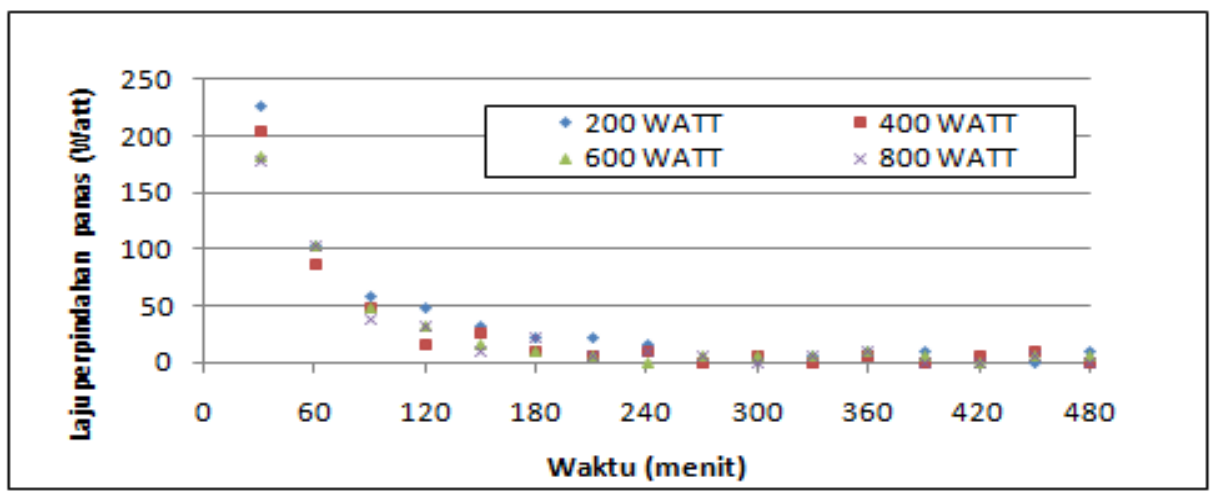

Gambar 4. Kalor PCM perwaktu pada setiap variasi Heater

Terlihat pada gambar 4, bahwa 30 menit pertama merupakan laju perpindahan panas PCM terbesar baik pada heater 200, 400, 600, dan 800 Watt. Besarnya nilai perpindahan panas terlihat pada heater 200 Watt sebesar 225,89 Watt, heater 400 Watt sebesar 204,38 Watt, heater 600 Watt sebesar 182,86 Watt, dan heater 800 Watt sebesar 177,49 Watt. Besarnya laju perpindahan panas pada PCM akan mengalami penurunan pada menit-menit berikutnya hingga mendekati tidak adanya perpindahan panas yang terjadi. Berdasarkan laju perpindahan kalor yang terjadi dapat dilihat bahwa PCM dapat mempertahankan beban termal ruangan. Hal ini senada dengan penelitian lain bahwa Bahan berubah fasa dapat menurunkan beban pendinginan pada ruangan dengan cara menyimpan kalor dari luar sehingga temperatur ruangan relatif lebih rendah dari bangunan yang tidak menggunakan bahan berubah fasa[9].

\section{Kesetimbangan Energi}

Energi kalor diperoleh dari hasil kali antara kalor yang pindah perwaktu dengan lamanya pemakaian. Dari hasil perhitungan jumlah energi kalor pada heater, $P C M$ dan $A C$, maka dapat dibuat kesetimbangan energi. Energi yang diserap oleh refrigerant $A C$ adalah sama atau lebih besar dari penjumlahan energi yang dikeluarkan oleh heater dan PCM. Menghitung jumlah energi digunakan persamaan sebagai berikut:

$$
Q_{A C} \geq Q_{\text {Heater }}+Q_{P C M}
$$

Keterangan:

$Q_{A C} \quad$ : Jumlah energi kalor $A C$ (Joule)

$Q_{\text {Heater }}$ : Jumlah energi kalor heater (Joule)

$Q_{P C M} \quad$ : Jumlah energi kalor PCM (Joule)

Berdasarkan hasil perhitungan energi yang didapatkan maka dapat dilihat kesetimbangan energi yang terjadi. Kesetimbangan energi pada penelitian ini akan dibandingkan antara energi yang diambil oleh $A C\left(Q_{\text {in }}\right)$ yakni perpindahan panas antara udara dan refigeran di evaporator $A C$ dengan energi yang dikeluarkan heater dan $P C M$ ( $\mathrm{Q}_{\text {out}}$ ). Perbandingan total energi yang dihasilkan masing-masing pengujian dapat dilihat pada Gambar 5.

Berdasarkan nilai yang dihasilkan dari total energi selama 8 jam pengujian dan dimasukkan dalam persamaan kesetimbangan energi maka akan memiliki kesetimbangan energi yang baik atau tidak ada rugi energi besar. Rugi-rugi energi yang terjadi dapat disebabkan oleh adanya kalor yang masuk dari luar ruangan baik dari dinding, maupun adanya udara luar masuk melalui celah-celah yang ada. Sedangkan pada kesetimbangan energi dengan daya heater kecil, terjadi selisih energi yang besar antara $Q_{\text {in }}$ dan $Q_{\text {out. }}$ Perbedaan energi disebabkan karena energi termal Qout (heater dan PCM) terjadi rugi-rugi yang disebabkan termal dari luar. Pengaruh termal dari luar terlihat pada grafik 
perbandingan temperatur ruangan, dimana terjadi temperatur ruangan yang tinggi pada heater daya kecil.

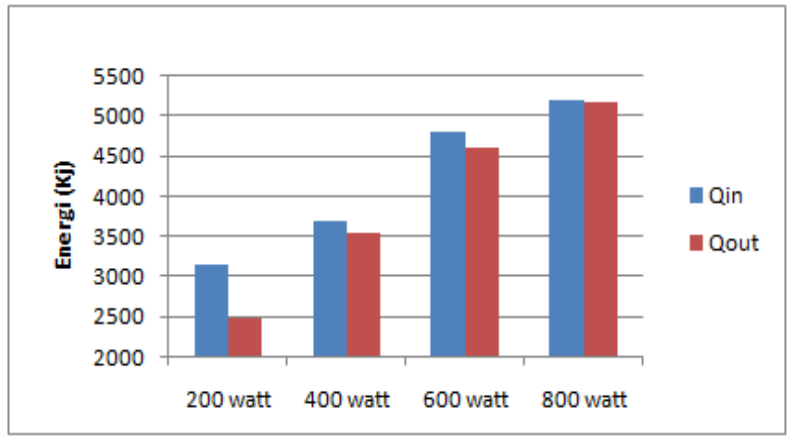

(a)

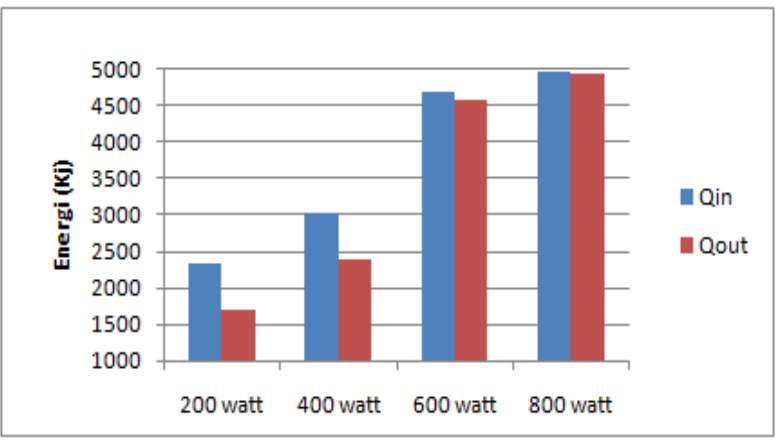

(b)

Gambar 5. Kesetimbangan energi pada setiap variasi temperatur $A C$ (a) Pengaturan $A C 20^{\circ} \mathrm{C},(\mathrm{b})$ Pengaturan $A C 22^{\circ} \mathrm{C}$

\section{Perbandingan Temperatur Ruangan}

Temperatur ruangan merupakan beban $A C$ yang dihasilkan dari peralatan yang terdapat pada suatu ruangan. Pada penelitian ini heater diasumsikan sebagai pengganti peralatan pada sebuah ruangan uji. Penelitian menggunakan tiga model ruangan untuk membandingkan perbedaan perlakuan, yaitu ruangan non partisi, ruangan berpartisi $P C M$, dan ruangan berpartisis $P C M$ dengan aliran udara malam.

Gambar 6 menunjukkan perbandingan temperatur ruangan selama 8 jam pengujian. Pada Gambar 6 (a) ruangan model non PCM menujukkan rata-rata temperatur ruangan sebesar $20,9^{\circ} \mathrm{C}$. Untuk ruangan berpartisi $P C M$ menujukkan rata-rata temperatur ruangan sebesar $19,53^{\circ} \mathrm{C}$. Sedangkan pada model ruangan berpartisi $P C M$ dengan udara malam rata-rata temperatur ruangan sebesar 19,14 ${ }^{\circ} \mathrm{C}$. Pada Gambar 6 (b) ruangan model non PCM menunjukkan rata-rata temperatur ruangan sebesar $21,67^{\circ} \mathrm{C}$. Untuk ruangan berpartisi $P C M$ rata-rata temperatur ruangan sebesar $21,69^{\circ} \mathrm{C}$. Sedangkan untuk model ruangan berpartisi $P C M$ dengan udara malam rata-rata temperatur ruangan sebesar $21,9^{\circ} \mathrm{C}$.

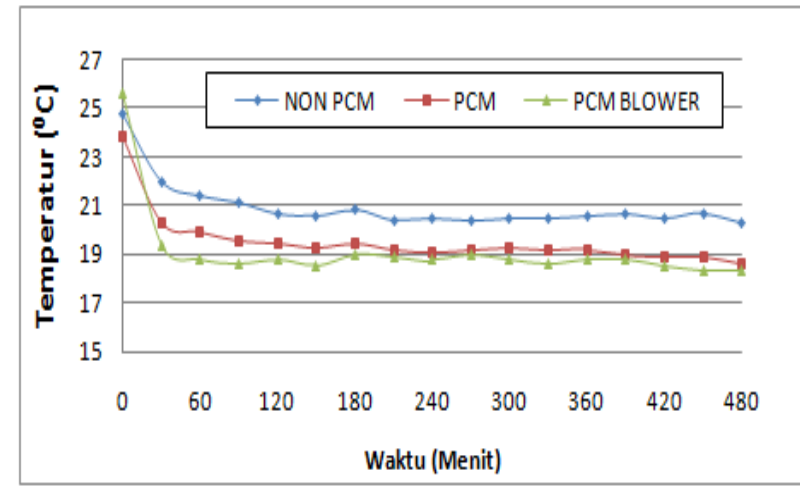

(a)

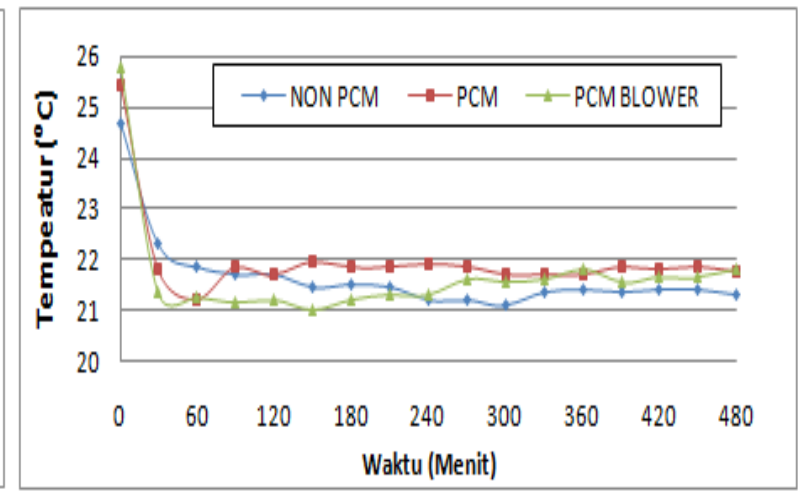

(b)

Gambar 6. Perbandingan temperatur ruangan terhadap variasi temperatur $A C$. (a) Pengaturan AC $20^{\circ} \mathrm{C}$, Heater $200 \mathrm{Watt}$, (b) Pengaturan AC $22^{\circ} \mathrm{C}$, Heater 200 Watt.

Berdasarkan hasil yang diperoleh dapat diartikan bahwa penggunaan PCM pada ruangan dapat menurunkan temperatur ruangan. Rendahnya temperatur yang dimiliki ruangan berpartisi PCM menunjukan bahwa terdapat pengaruh pada penggunaanya. Hal ini juga terlihat pada penggunaan partisi PCM dengan udara malam yang memiliki nilai terndah. 
Rendahnya temperatur ruangan menunjukkan beban termal $A C$ akan semakin kecil. Perbandingan temperatur ruangan pada variasi heater dapat dilihat pada gambar 7 .

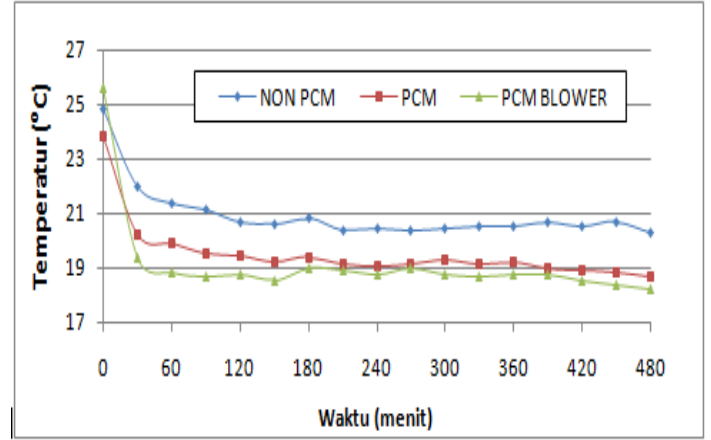

(a)

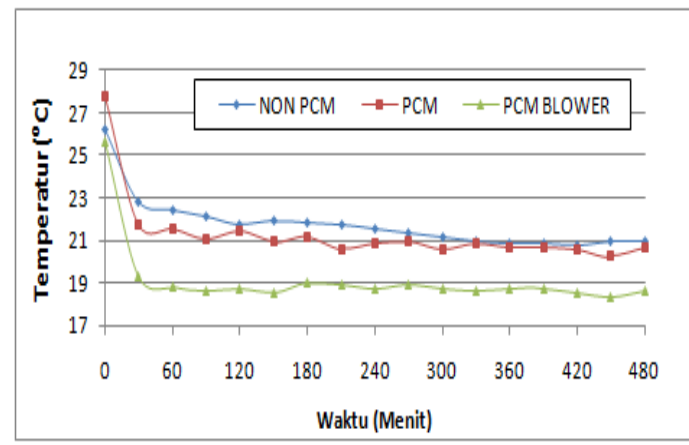

(c)

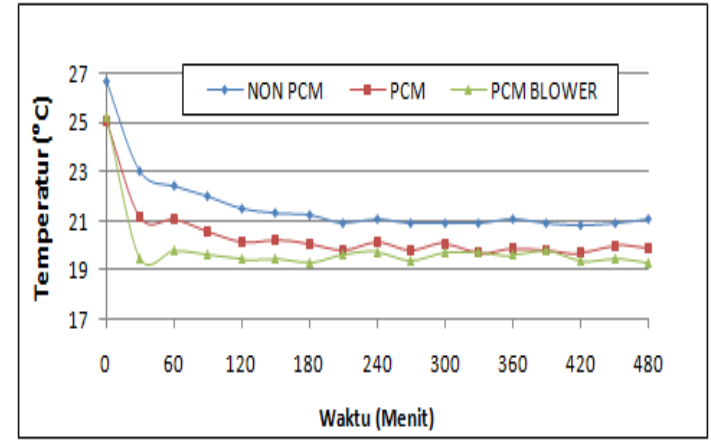

(b)

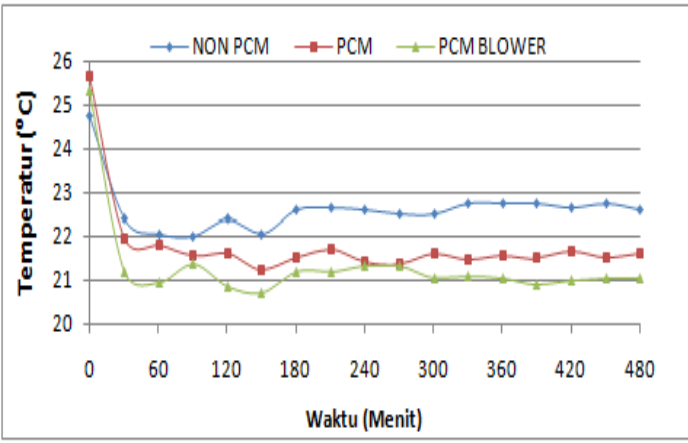

(d)

Gambar 7. Perbandingan temperatur ruangan terhadap variasi Heater pada Temperatur $20^{\circ} \mathrm{C}$. (a) Pengaturan heater 200 Watt, (b) Pengaturan heater 400 Watt, (c) Pengaturan heater 600 Watt,(d) Pengaturan heater 800 Watt.

Gambar 7 menujukkan pengaruh penggunaan PCM pada variasi heater. Dari hasil yang didapatkan terlihat adanya penurunan temperatur ruangan pada semua variasi heater. Temperatur ruangan pada heater 200 Watt yaitu $20,96^{\circ} \mathrm{C}$ untuk ruangan Non PCM, temperatur $19,53^{\circ} \mathrm{C}$ untuk ruangan berpartisi PCM, dan temperatur $19,14{ }^{\circ} \mathrm{C}$ untuk berpartisi PCM dengan udara malam. Pada heater 400 Watt yaitu $21,62^{\circ} \mathrm{C}$ untuk ruangan Non PCM, temperatur $20,43^{\circ} \mathrm{C}$ untuk ruangan berpartisi $\mathrm{PCM}$, dan temperatur $19,89^{\circ} \mathrm{C}$ untuk berpartisi PCM dengan udara malam. Sedangkan pada heater 600 Watt yaitu $21,79^{\circ} \mathrm{C}$ untuk ruangan Non PCM, temperatur $21,33^{\circ} \mathrm{C}$ untuk ruangan berpartisi $\mathrm{PCM}$, dan temperatur $19,16^{\circ} \mathrm{C}$ untuk berpartisi PCM dengan udara malam. Dan untuk heater $800 \mathrm{Watt}$ yaitu $22,63^{\circ} \mathrm{C}$ untuk ruangan Non PCM, temperatur $21,80^{\circ} \mathrm{C}$ untuk ruangan berpartisi $\mathrm{PCM}$, dan temperatur $21,33^{\circ} \mathrm{C}$ untuk berpartisi PCM dengan udara malam.

Berdasarkan hasil temperatur yang didapat pada perbandingan ruangan dengan memvariasikan heater dapat disimpulkan bahwa, pengunaan PCM memiliki dampak untuk penurunan temperatur ruangan. Hal ini dibuktikan dengan perbedaan temparatur yang lebih rendah antara ruangan yang tidak berpartisi $P C M$ dengan ruangan berpartisi $P C M$. Untuk ruangan berpartisi $P C M$ dengan udara malam juga memiliki nilai yang rendah meski belum terlalu terlihat besar perbedaan dengan yang tidak mengunakan udara malam.

\section{Analisis pemakaian Energi listik}

Pemakaian energi AC diukur menggunakan wattmeter dengan satuan $\mathrm{kWh}$ yang akan muncul pada layar dan akan dicatat pertambahan energi yang dipakai setiap 30 menit selama 8 jam pemakaian AC. Pengukuran daya $\mathrm{AC}$ dilihat dari variasi pengaturan $\mathrm{AC} 18^{\circ} \mathrm{C}, 20^{\circ} \mathrm{C}$, dan 
$22^{\circ} \mathrm{C}$ pada beban heater 800 watt. Setiap perpengaturan AC dilihat juga perbandingan dari model ruangan Non PCM, ruangan berpartisi PCM, dan ruangan partisi PCM dengan udara malam. Energi yang dipakai AC merupakan total daya yang digunakan selama pemakaian AC. Perhitungan energi yang digunakan AC dalam kurun waktu 8 jam pemakaian dapat dihitung menggunakan persamaan di bawah ini.

$$
\mathbf{E}=\mathbf{P} \cdot \mathbf{t}
$$

Keterangan:

E $\quad$ : Energi $A C /$ Blower (Joule)

$\mathrm{P} \quad$ : Daya (Watt)

t : Waktu (secon)

Hasil pengukuran daya yang dipakai AC saat beroperasi dapat dilihat pada Gambar 8.

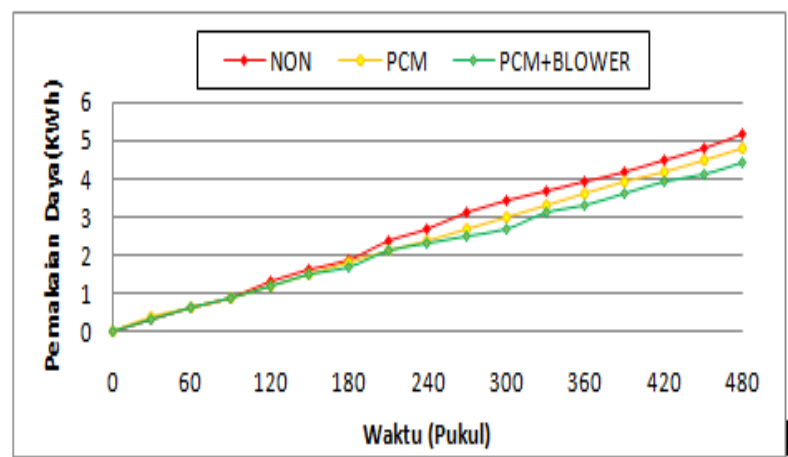

(a)

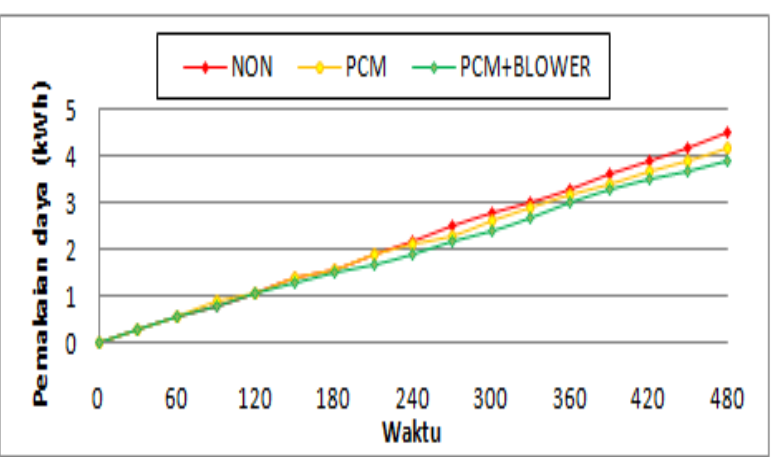

(b)

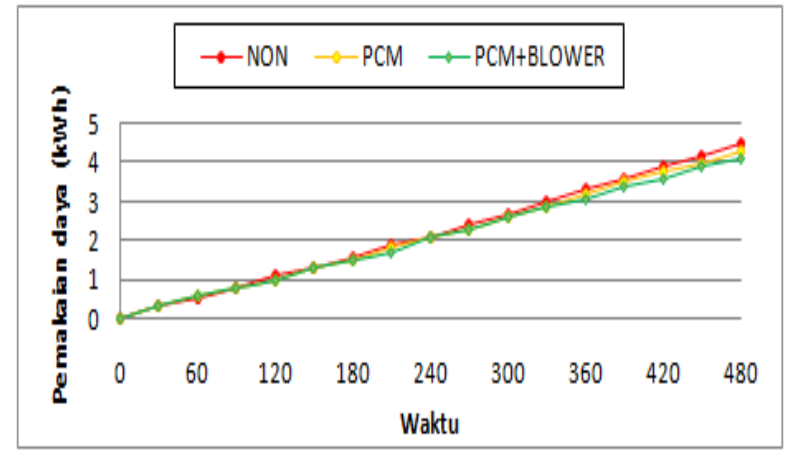

(c)

Gambar 8. Konsumsi pemakaian energi litrik AC pada tiap pengaturan. (a) Pengaturan $18^{\circ} \mathrm{C}$ dan heater 800 Watt (b) Pengaturan $20^{\circ} \mathrm{C}$ dan heater 800 Watt (c) Pengaturan $22^{\circ} \mathrm{C}$ dan heater 800 Watt

Pemakaian $P C M$ pada ruangan yang memiliki $A C$ dapat menurunkan energi listrik yang dipakai. Hal tersebut dapat dilihat dari gambar pemakaian energi listrik diatas. Berdasarkan masing-masing perlakukan ditujukan bahwa pemakaian PCM dapat menurunkan energi yang digunakan AC. Pemakaian PCM mengurangi beban termal ruangan sehingga beban AC akan semakin berkurang, karena itulah konsumsi energi dari $A C$ juga mengalami penurunan. Sedangkan dari kedua model ruangan antara ruangan berpartisi PCM dengan ruangan berpartisi PCM dengan udara malam juga terdapat perbedaan. Pada gambar dapat terlihat bahwa pada model PCM dengan udara malam lebih efektif penurunan konsumsinya bisa mencapai $15,4 \%$. Dengan demikian dapat disimpulkan bahwa pemakian PCM pada partisi dinding dapat membantu mengurangi konsumsi energi listrik AC. Dengan demikian pengunaan PCM pada apartisi dinding dapat mengurangi beban termal dari ruangan sehingga beban AC akan semakin ringan. Hal ini senada dengan penelitian lain bahwa jika 
penyimpanan termal dirancang dengan baik, maka dapat mengurangi penggunaan energi listrik dengan biaya yang murah [10]

\title{
Pemakaian energi listrik pada Blower
}

Penggunaan blower sebagai media untuk memasukan udara malam dari luar ke dalam ruangan tentunya akan menjadi tambahan pemakaian energi listrik. Blower akan bekerja selama tiga jam setiap malamnya. Dengan daya 250 watt yang dimiliki blower maka dapat diketahui energi yang dipakai untuk bekerja sebesar 750 Watt. Pemakaian energi listrik total pada yaitu penjumlahan energi yang digunakan AC selama 8 jam bekerja di siang hari dengan penggunaan blower selama 3 jam pada malam hari. Energi total didapat dengan persamaan dibawah ini:

\section{$\mathbf{E}_{\text {Total }}=\mathbf{E}_{A C}+$ EBlower}

\author{
Keterangan: \\ ETotal : Energi total keseluruhan yang dipakai \\ $\mathrm{E}_{A C}$ : Energi yang dipakai $A C$ \\ EBlower : Energi yang dipakai blower
}

Berdasarkan perhitungan diperoleh energi total untuk masing-masing variasi pengujian. Energi total yang digunakan pada pengujian $\mathrm{AC} 18{ }^{\circ} \mathrm{C}$ dengan beban heater 800 Watt yaitu sebesar 5150 Watt. Untuk pengujian dengan AC $20^{\circ} \mathrm{C}$ dengan beban heater 800 Watt yaitu sebesar 4850 Watt. Sedangkan pada pengujian AC $22^{\circ} \mathrm{C}$ dengan beban heater 800 Watt yaitu sebesar 4650 Watt. Penggunaan udara malam hari dan PCM pada ruangan masih membutuhkan energi lebih besar dibandingkan dengan pendinginan ruangan hanya menggunakan AC. Belum efektifnya model aplikasi ini disebabkan karena temperatur udara dingin malam hari masih tinggi.

\section{SIMPULAN DAN SARAN}

\section{Simpulan}

Berdasarkan hasil penelitian penggunaan Phase Change Matrials (PCM) jenis minyak kelapa dan pemanfaatan udara malam sebagai pendingin ruangan maka dapat ditarik kesimpulan sebagai berikut.

Beban termal sebuah ruangan sangat mempengaruhi proses pendinginan PCM minyak kelapa (Barco). Hal tersebut terlihat pada analisis laju perpindahan panas yang diterima $P C M$, dimana semakin besar beban termal ruangan yang ada maka nilai laju perpindahan panas dari $P C M$ semakin tinggi. Nilai puncak laju perpindahan panas terlihat pada 30 menit pertama mencapai 420 Watt pada heater 800 Watt, 370 Watt pada heater 600 Watt 340 Watt pada heater 400 Watt, dan 330 Watt pada heater 200 Watt.

Pengaruh penurunan energi yang dikonsumsi $A C$ pada pemanfaatan $P C M$ terlihat pada grafik perbandingan ruangan (Non $P C M$, berpartisi $P C M$, berpartisi $P C M$ dengan udara malam). Penurunanan yang dicapai menunjukan nilai 800 Watt untuk $A C 20^{\circ} \mathrm{C}$, dan 400 Watt untuk $A C 22^{\circ} \mathrm{C}$ selama pemakaian 8 jam dengan beban ruangan 800 watt.

\section{Saran}

Berdasarkan penelitan yang telah dilakukan dan hasil yang didapatkan, maka saran yang dapat diberikan untuk penelitan berikutnya adalah sebagai berikut:

Disarankan lakukan pengujian pada wilayah yang memiliki suhu temperatur yang sesuai dengan kriteria perubahan fasa matrial yang digunakan agar pengaruh pengunaan PCM lebih terlihat. 
Disarankan pemilihan blower udara yang tidak menimbulkan kenaikan temperatur udara, sehingga udara yang masuk tidak terjadi kenaikan temperatur suhu.

Disarankan agar dilakukan pengulangan pada setiap variasi yang diambil agar dapat dibandingkan dengan data yang diambil sebelumnya supaya data yang di hasilkan tersebut lebih tepat.

\section{DAFTAR RUJUKAN}

[1] Badan Standar Nasional (BSN) Tentang Konservasi Energi Sistem Tata Udara Bangunan Gedung: SNI 6390:2011

[2] Hermanto, dkk. (2005). "Pengembangan Metode Simulasi Sistem Pengkondisian Udara Energi Surya": Jurnal Teknik Mesin Volume 20, Vol.20, 58-67

[3] Badan Standar Nasional (BSN) Tentang Konservasi Energi Sistem Tata Udara Bangunan Gedung : SNI 6390:2011

[4] Pasupathy, dkk (2008) "Phase change material-based building architecture for thermal management in residential commercial establishments" : Elsevier journal, Renewable and Sustainable Energy Reviews 12 (2008) 39-64

[5] Kasaein, Alibakhsh dkk (2017) "Experimental studies on the applications of PCMs and nanoPCMs in buildings": A critical review: Energy and Buildings 154 (2017) 96-112.

[6] Irsyad,dkk (2017) "Heat Transfer Characteristics of Coconut Oil As Phase Change Material To Room Cooling Application" : IOP Conference Series: Earth and Environmental Science , Vol 60, (2017) Page 012027.

[7] Osterman, dkk (2012) "Review of PCM based cooling technologies for buildings" : Energy and Buildings, Vol 49, (2012) Page 37-49

[8] Mursalim, dkk (2013) Fraksinasi kering minyak kelapa menggunakan kristalisator skala $120 \mathrm{~kg}$ untuk menghasilkan fraksi minyak kaya triasilgliserol rantai menengah : Jurnal Littri Volume 19 (1), Maret 2013. Hlm. 41-49 ISSN 0853-8212

[9] Lia Laila (2016) Pemanfaatan Sistem Pengondisian Udara Pasif dalam Penghematan Energi : SANIATI ISSN : 2085-4218

[10] Rismanchi, Behza (2017) A review on cool thermal storage technologies and operating strategies : Renewable and Sustainable Energy Reviews 16 (2017) 787- 797 